\title{
miR-100 Reverses Cisplatin Resistance in Breast Cancer by Suppressing HAX-1
}

\author{
Guojun Wu $\mathrm{W}^{\mathrm{a}}$ Wenhong Zhou ${ }^{\mathrm{b}}$ Xiaohua Pan ${ }^{\mathrm{a}}$ Yongjie Sun \\ Peng Shi ${ }^{a}$ Jiyu Lia Ling Gao ${ }^{c}$ Xingsong Tian ${ }^{a}$
}

aDepartment of Breast and Thyroid Surgery, Shandong Provincial Hospital Affi' University, Jinan, Shandong, 'Department of Nursing, Shandong Provincial Ho. Shandong University, Jinan, Shandong, 'Scientific Center, Shandor incial Ho Shandong University, Jinan, Shandong, China

\section{Key Words}

miR-100 $\bullet \mathrm{HAX}-1 \cdot$ Cisplatin $\bullet$ Resistance $\bullet$ Breac

\section{Abstract \\ Background/Aims: Breast cancer (BC) Despite great advancements in cance are still the mainstays of $B C$ treatme} to evade cell death induced chemoresistance of cancer $C$ MDA-MB-231 and MCF-7 reverse transcription $\mathrm{PC}$ cell viability assays were cell-specific protein 1 ass western blottin apoptosis wer ne into the detecte weste
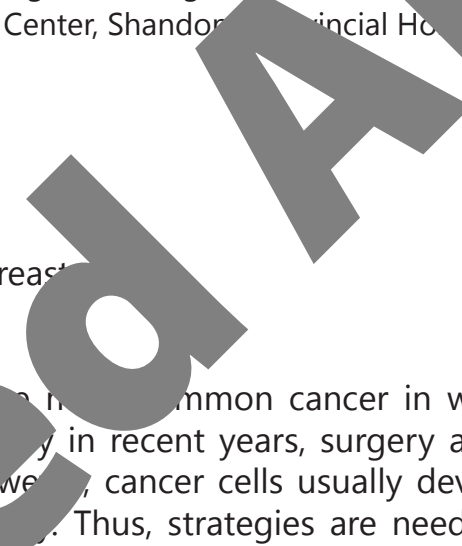
as used examine the expression of microRNA (miR)-100. MTT form $d$ to determine cell viability. Regulation of hematopoietic orotein X-1 (HAX-1) targeted by miR-100 was confirmed by iferase reporter assays. The mitochondrial membrane potential and y flow cytometry. Release of cytochrome c from the mitochondria j crola sistant MDA-MB-231 and MCF-7 cells (MDA-MB-231/R and MCF-7/R). xpres f miR-100 increased the sensitivity of MDA-MB-231/R and MCF-7/R cells tip treatment and promoted cisplatin-induced mitochondrial apoptosis by targeting AX- Conclusions: MiR-100 targeted HAX-1 to increase the chemosensitivity of BC by diating the mitochondrial apoptosis pathway.

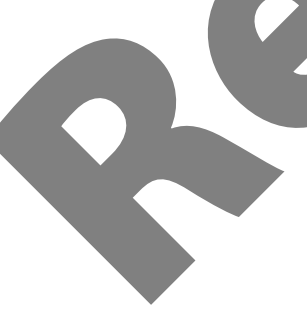

\section{Introduction}

Breast cancer (BC) is the most common cancer in women worldwide. It causes high mortality because of metastatic spread of the cancer cells to vital organs [1,2]. Currently, Guojun Wu and Wenhong Zhou contributed equally to this study.

Ling Gao
and Xingsong Tian
Scientific Center, Shandong Provincial Hospital Affiliated to Shandong University

No. 324, Jing 5 Road, Jinan, Shandong 250021, (China)

E-Mail gaoling8822@sina.com and xingsong_tianxs@sina.cn

\section{KARGER}




\section{Cellular Physiology Cell Physiol Biochem 2018;47:2077-2087 \begin{tabular}{ll|l} 
and Biochemistry & $\begin{array}{l}\text { DOI: 10.1159/000491476 } \\
\text { Published online: July 04, } 2018\end{array}$ & $\begin{array}{l}\text { ( ) } 2018 \text { The Author(s). Published by S. Karger AG, Basel } \\
\text { www.karger.com/cpb }\end{array}$ \\
\hline
\end{tabular} \\ Wu et al.: miR-100 Reverses Cisplatin Resistance}

surgical resection and chemotherapy are still the main treatment strategies for this disease $[3,4]$. However, many patients with BC exhibit a poor response to systematic chemotherapy $[5,6]$. Thus, there is an urgent need to develop strategies that reverse the chemoresistance of BC cells.

Cisplatin is an effective broad-spectrum platinum-based anticancer drug used for treatment of various cancers, including BC. Its mechanism of action involves binding $t$ DNA nucleobases and inducing DNA damage by forming platinum-DNA adducts that trigger apoptosis in cancer cells $[7,8]$. However, continuous exposure to cisplatin can cause car cells (including BC cells) to develop mechanisms to survive cisplatin treatment [0-11]. T novel interventions are required to reverse chemoresistance to cisplatin in $\mathrm{BC}$

MicroRNAs (miRNAs) are a class of endogenously expressed and non-ce RNAs that suppress gene expression by binding to the $3^{\prime}$ untranslated of target miRNAs. Studies have reported that dysregulation of miRNAs tumorigenesis and cancer development, because miRNAs participate in bin logical processes, including cell proliferation, differentiation, and apoptosin $2-14$ eover, dysregulation of miRNAs induces cisplatin resistance in many cancer uding $B C[15,16]$. Therefore, targeting dysregulated miRNAs may be a pote strateg, improving the efficiency of cisplatin therapy.

In this study, we investigated the ability of miRN nik $>$ potential tumor suppressor, to reverse cisplatin resistance in BC.

\section{Materials and Methods}

\section{Cell culture}

Human breast cancer cell lines MDA-MB-231 an Collection (Manassas, VA) and cultured at $37^{\circ} \mathrm{C}$ be Afied Eagle's medium (Gibco, Gaithersburg MD) supplemented with $10 \%$ fetal bovine se 110 Gibco) In a humidified $5 \% \mathrm{CO}_{2}$ incubator. To establish cisplatin-resistant BC models, MDA-MB-23 ells were exposed to increasing concentrations of cisplatin (Sigma-Aldrich, Darmst initially treated with $1 \mu \mathrm{M}$ cisplat montro, and the cisplatin concentration was increased every 3 weeks by $0.2 \mu \mathrm{M}$ to a final con ${ }^{\circ}$ trath

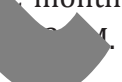

\section{Quantitative reverse tr ciption teal time PCR}

TotalRNAwasextmacted.

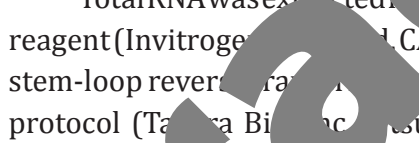

CA).ror analysis of miR-100 expression, total RNA was reverse transcribed using

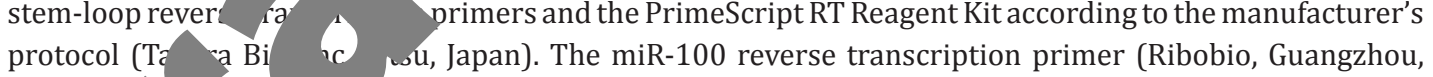
China) b for sequence: 5'-CTCAACTGGTGTCGTGGAGTCGGCAATTCAGTTGAGCATACCTA-3'. $\mathrm{S}^{\prime} \mathrm{BR}^{\circledR} \mathrm{Pr} \quad \mathrm{T}$ Taq II Reagent (Takara) was used for PCR amplification of miR-100 using the Applied ems T Thermocycler (Thermo Fisher Scientific, Waltham, MA). The relative expression of was no malized to U6 snRNA and determined according to $2^{\text {-घ⿴囗十 }}$ analysis [17].

or knockdown of hematopoietic cell-specific protein 1-associated protein X-1 (HAX-1), HAX-1 small ering RNA (siRNA) was purchased from Santa Cruz Biotechnology (Dallas, TX). To overexpress AX-1, recombinant pcDNA3.1 plasmid (Invitrogen) containing the HAX-1 open reading frame was used. For transfection, $2 \mu \mathrm{g} / \mathrm{mL}$ HAX-1 vector, $50 \mathrm{pmol} / \mathrm{mL}$ HAX-1 siRNA, $50 \mathrm{pmol} / \mathrm{mL}$ miR-100 mimics (5'-CAAGCUUGUAUCUAUAGGUAUG-3', GenePharma Co., Ltd., Shanghai, China) and $50 \mathrm{pmol} / \mathrm{mL}$ negative control oligonucleotide (NCO, 5' -CUUAUGAGAUCACGUAGUAUGU-3'; GenePharma Co., Ltd.) were transfected into BC cells using Lipofectamine ${ }^{\mathrm{TM}} 2000$ (Invitrogen) according to the manufacturer's instructions.

Luciferase reporter assay

HAX-1 3' UTR containing the putative miR-100 binding site was cloned downstream of the firefly luciferase gene in the pMIR-REPORT T⿳㇒⿴囗十 miRNA Expression Reporter Vector (Thermo Fisher Scientific) and 


\section{Cellular Physiology Cell Physiol Biochem 2018;47:2077-2087

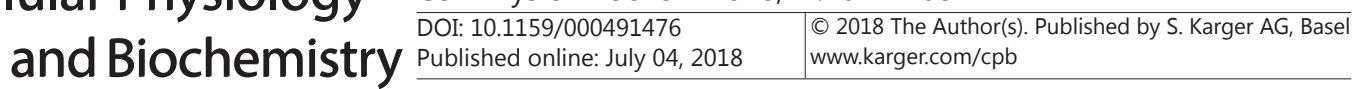 \\ Wu et al.: miR-100 Reverses Cisplatin Resistance}

designated pMIR-HAX-1. To perform the luciferase reporter assay, cells were incubated in 48-well plates overnight at $37^{\circ} \mathrm{C}$. Then, cells were co-transfected with pMIR-HAX-1 and Renilla Luciferase pRL-TK vectors (Promega Corp., Madison, WI) and miR-100 mimics using Lipofectamine 2000. At 48 h post-transfection, the luciferase activities were measured using the Dual Luciferase Reporter Assay System (Promega Corp.) according to the manufacturer's instructions.

\section{Cell viability assay}

BC cells were seeded in 96 -well plates at a density of $5 \times 10^{3}$ cells per well overnight at $37^{\circ} \mathrm{C}$. Subseque the cells were treated with different concentrations of cisplatin, carboplatin, and oxaliplatin for $48 \mathrm{l}$ viability was evaluated using the 3-(4, 5-dimethylthiazol-2-yl)-2, 5-diphenyltetrazolium assay as previously described [18]. The absorbance was read at $570 \mathrm{~nm}$ using a microplate re (I) of cisplatin, carboplatin, and oxaliplatin was to the cell viability curve of BC cells.

\section{Western blot analysis}

Cells were lysed in RIPA lysis buffer (Cell Signaling Technology [CST], Inc., $50 \mu \mathrm{g}$ total proteins were separated by $12.5 \%$ sodium dodecyl sulf - lvacrylan and transferred to a polyvinylidene fluoride membrane (EMD Millip MA). $\quad$, the membranes were incubated with primary antibodies (anti-HAX-1, GAPDH, cyto me complex IV [COXIV], caspase-9, and caspase-3; CST) overnight at $4^{\circ} \mathrm{C}$. Next, the membran in sated with appropriate horseradish peroxidase-conjugated secondary antibor for $2 \mathrm{~h}$ follov y detection with an enhanced chemiluminescence detection kit (Pierce Biotechnology, ford, IL).

Mitochondrial membrane potential and apoptosi, ectro

For detection of the mitochondrial membrane $\mathrm{p}$ tial $s$, cells were collected and stained with JC-1 (Molecular Probes, Thermo Fisher Scien as tor before analysis of $\Delta \Psi_{\mathrm{m}}$ by flow cytometry (Becton Dickinson, Franklin Lake jo ding to the manufacturer's instructions. To measure the apoptotic rate, cells were collected ar th annexin V/propidium iodide (Sigma-Aldrich). Subsequently, cell apoptosis was $\quad \mathrm{d} b$ netry and annexin V-positive cells were considered to be apoptotic BC cells.

Tumor growth in nude r

Lentivirus expressing based system (Genechem C tumorigenesis ass inoculation into de with intrape neal bla

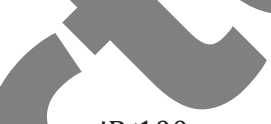
miR`00 precursor (LV-miR-100) was generated using a lentiviralanghai, China) according to the manufacturer's instructions. For MB- $-1 / \mathrm{R}$ cells were transfected with empty lentivirus or LV-miR-100 before $\mathrm{B} / \mathrm{c}, \mathrm{nu} / \mathrm{nu}$ ). After xenografts reached $0.5 \mathrm{~cm}$ in diameter, mice were treated care and cocols were approved by the Animal Care Committee of Shandong Provincial thispital L ed to Shandong University (Jinan, China).

represented as the mean \pm standard deviation, and were obtained from three independent
go, IL). $P<0.05$ was considered statistically significant.

\section{Results}

Decrease of miR-100 in cisplatin-resistant BC cells

To investigate the potential role of miR-100 in cisplatin resistance in $\mathrm{BC}$, we first established cisplatin-resistant BC models in MDA-MB-231 and MCF-7 cell lines (MDA-MB231/R and MCF-7/R, respectively). As shown in Fig. 1A, MDA-MB-231/R and MCF-7/R cells exhibited significant cisplatin resistance compared with their parental MDA-MB-231 


\section{Cellular Physiology Cell Physiol Biochem 2018;47:2077-2087 \begin{tabular}{ll|l} 
and Biochemistry & $\begin{array}{l}\text { DOI: 10.1159/000491476 } \\
\text { Published online: July 04, } 2018\end{array}$ & $\begin{array}{l}\text { ( ) } 2018 \text { The Author(s). Published by S. Karger AG, Basel } \\
\text { www.karger.com/cpb }\end{array}$ \\
\hline
\end{tabular}

and MCF-7 cells, respectively. Next, we detected changes in miR-100 expression in these BC cell lines, and found that miR100 expression was decreased in both cisplatin-resistant BC models (Fig. 1B). These results suggested that the decrease in miR-100 expression was associated with cisplatin resistance in $\mathrm{BC}$.

Recovery of miR-100 increased the sensitivity of cisplatin-resistant $B C$ cells to cisplatin treatment

Because miR-100 expression was decreased in cisplatin-resistant $\mathrm{BC}$ cells, we transfected MDA-MB-231/R and MCF-7/R cells with miR100 mimics to restore miR-100 levels in both cell lines (Fig. 2A). Results of the MTT assay showed that restoration of miR100 expression significantly increased the sensitivity of MDAMB-231/R and MCF-7/R cells to cis of miR-100 in cisplatin-indy expression in MDA-MB-231

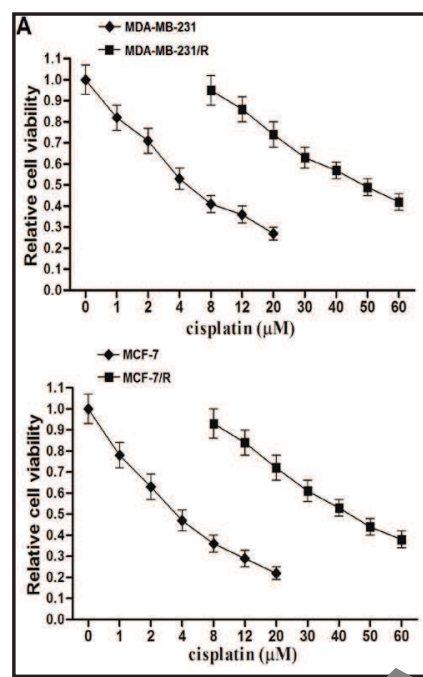

Fig. 1. Expression of $\mathrm{mi}^{\mathrm{r}}$ After treatment with diff $\mu \mathrm{M})$, the viability of MDAMCF-7/R cells was detected $u$ against MDF 31, MDA-ME was calculated ding to the 11 viability curves $(* \mathrm{P}<0.05)$. B: Quantitative nscription PCR analysis was performed to detect th press miR-100 in MDA-MB-231, MDA-MB231/R, MCF (anti-miR-100) (Fig. 2C). decreased cisplatin sen vity to BC cells (Fig. 2D). These results suggested that restoration of miR-100 rsed 'splatin resistance in BC cells.

MiR-100 to $4 X-1$ - $B C$

To explor se ism by which miR-100 reversed cisplatin resistance, we performed a series of alys at atify the molecular target of miR-100 in BC. Data from TargetScan, a publir NA p con database, showed that the HAX-1 gene contained a seed region p'ired in iR-100 in the 3' UTR of its mRNA (Fig. 3A). Previous studies have reported that ove assion decreases apoptosis and promotes the survival of $\mathrm{BC}$ cells; thus, we on the elationship between miR-100 and HAX-1 in BC $[20,21]$. Western blot analysis MDA-MB-231/R and MCF-7/R cells expressed clearly higher levels of HAX-1 at hown in Fig. 1B led us to speculate that HAX-1 overexpression in cisplatin-resistant BC may have been induced by downregulation of miR-100 in these cells. For confirmation, ve transfected the $\mathrm{BC}$ cells with miR-100 before detection of HAX-1 protein expression. We observed that miR-100 expression decreased HAX-1 levels in MDA-MB-231/R, MCF-7/R, MDA-MB-231/R, and MCF-7/R cells (Fig. 3C). The results of the luciferase reporter assay showed that co-transfection with miR-100 decreased the luciferase activities of pMIRplasmid carrying HAX-1 3' UTR (Fig. 3D). Taken together, these data confirmed that miR-100 targets HAX-1 in BC. In addition, overexpression of HAX-1 in cisplatin-resistant BC cells may be induced by decreasing miR-100 levels. 


\section{Cellular Physiology \\ Cell Physiol Biochem 2018;47:2077-2087 and Biochemistry

Fig. 2. Effects of miR-100 on decreasing cisplatin resistance in BC. A: Transfection with miR-100 mimics (50 pmol/mL) increased the cellular level of miR-100 in MDA-MB-231/R and MCF-7/R cells $\left({ }^{*} \mathrm{P}<0.05\right)$. B: Transfection with miR$100 \mathrm{mimics}(50 \mathrm{pmol} / \mathrm{mL}$ ) increased the sensitivity of MDA-MB-231/R and MCF-7/R cells to cisplatin (10 $\mu \mathrm{M})$ treatment $\left({ }^{*} \mathrm{P}<0.05\right.$ vs. cisplatin + negative control oligonucleotide [NCO] group). C: Transfection with anti-miR-100 (50 pmol/mL) decreased the cellular level of miR100 in MDA-MB-231 and MCF-7 cells $\left({ }^{*} \mathrm{P}<0.05\right)$. D: Transfection with anti-miR-100 mimics $(50$ pmol/ $\mathrm{mL}$ ) decreased the sensitivity of MDA-MB-231 and MCF-7 cells to cisplatin + NCO group).
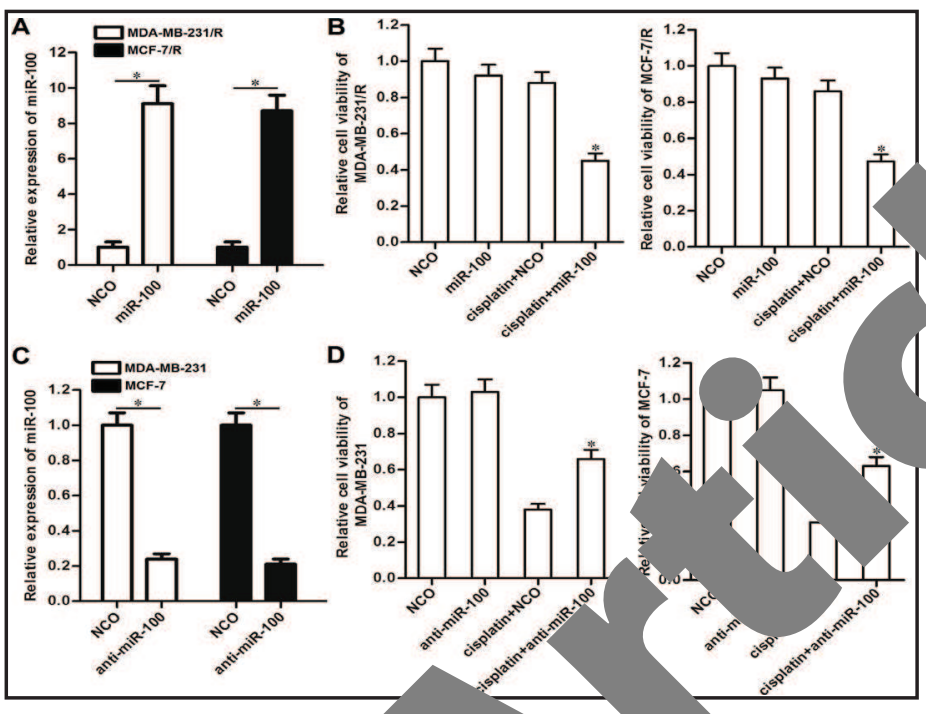

Fig. 3. miR-100 targeted HAX-1 in BC. A: Seed region of HAX-1 3' UTR paired with miR-100. B: Protein expression of HAX-1 in MDAMB-231, MDA-MB-231/R, MCF-7, and MCF-7/R cell lines. C: Effects of miR-100 mimics (50 pmol/mL) on inhibiting HAX-1 expression in MF MB-231/R and MCF-7/R cells. After co-transfection with $\mathrm{mi}^{{ }^{2}} \mathrm{Ou}$ and pMIR-plasmid carrying $\mathrm{X}-1$ 3' UTR in MDA-MB-231/R a

$7 / \mathrm{R}$ cells, luciferase ontivitic measured using th Reporter Assay ds ding to the man ture in uctions

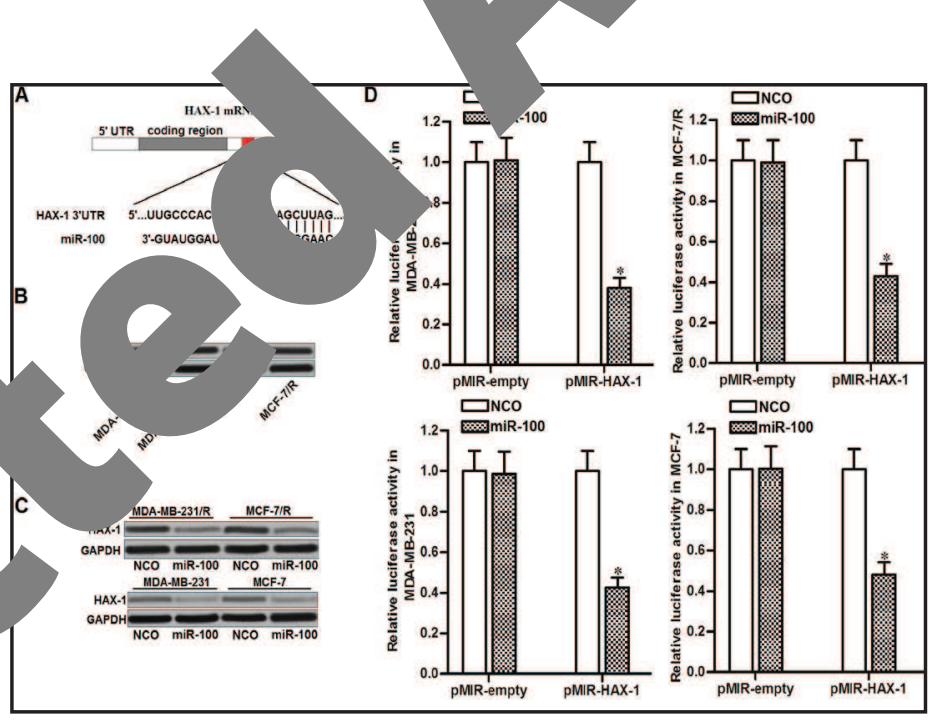
$\left({ }^{*} \mathrm{P}<0.05 \quad \mathrm{O}\right.$ gro

$R-1 . \quad$ ersed cisplatin resistance in BC cells by suppressing the HAX-1 pathway explo the importance of HAX-1 in the induction of cisplatin resistance in $\mathrm{BC}$, ed gain-of-function and loss-of-function experiments. As shown in Fig. 4A,
asfecuon with the HAX-1 eukaryotic expression vector abolished the effects of miRof an decreasing HAX-1 expression. Meanwhile, transfection with HAX-1 siRNA clearly ressed HAX-1 expression in MDA-MB-231/R and MCF-7/R cells. Overexpression of AX-1 partially "rescued" MDA-MB-231/R and MCF-7/R cells co-treated with cisplatin and miR-100. Conversely, knockdown of HAX-1 using specific siRNA enhanced the cytotoxicity of cisplatin against MDA-MB-231/R and MCF-7/R cells, similar to miR-100 (Fig. 4B). Both HAX-1 siRNA and miR-100 enhanced cisplatin-induced apoptosis in MDA-MB-231/R and MCF-7/R cells. However, miR-100-mediated cisplatin-induced apoptosis could be inhibited by HAX-1 overexpression in these cisplatin-resistant BC cells (Fig. 4C). Taken together, these results indicate that the miR-100/HAX-1 axis is an important pathway for determining the sensitivity of cisplatin-resistant BC cells to cisplatin-induced apoptosis. Restoration of miR100 may represent a potential approach for reversing cisplatin resistance in BC. 


\section{Cellular Physiology Cell Physiol Biochem 2018;47:2077-2087

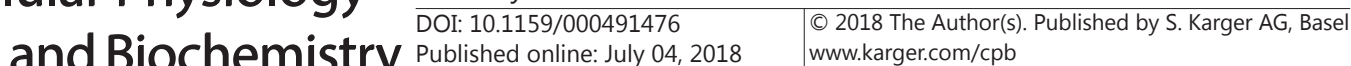 \\ Wu et al.: miR-100 Reverses Cisplatin Resistance}

MiR-100 increased the
sensitivity of cisplatin-
resistant BC cells to
cisplatin-ind c c d
mitochondrial apoptosis
The overexpression of HAX-1 inhibits mitochondrial outer membrane permeabilization (MOMP) in cancer cells [22]. Therefore, we investigated the role of the miR-100/HAX-1 axis in cisplatin-induced apoptosis in cisplatin-resistant BC cells. Flow cytometry analysis showed that cisplatin treatment induced a slight decrease of $\Delta \Psi$ in MDA-MB$231 / R$ and MCF-7/R cells. However, combination with miR-100 clearly promoted the cisplatin-induced collapse of $\Delta \Psi_{\mathrm{m}}$ (Fig. 5A). Furthermore, co-treatment with miR-100 was promoted release of cytochrome $\mathrm{c}$ in cisplatin-treated MDA-MB231/R and MCF-7/R ce (Fig. 5B). The results showe that combination treat nc with cisplatin and $\mathrm{m} \quad 00$ significantly increase the expression of cacnasecaspase-3, whic executors in $D$ and $1 / \mathrm{R}$

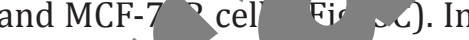
addition over ssion of $\mathrm{H}^{\mathrm{M}} \mathrm{X}-\mathrm{T}-\mathrm{in}$ ed the apoptotic ay DA-MB-231/R F-7/h cells co-treated

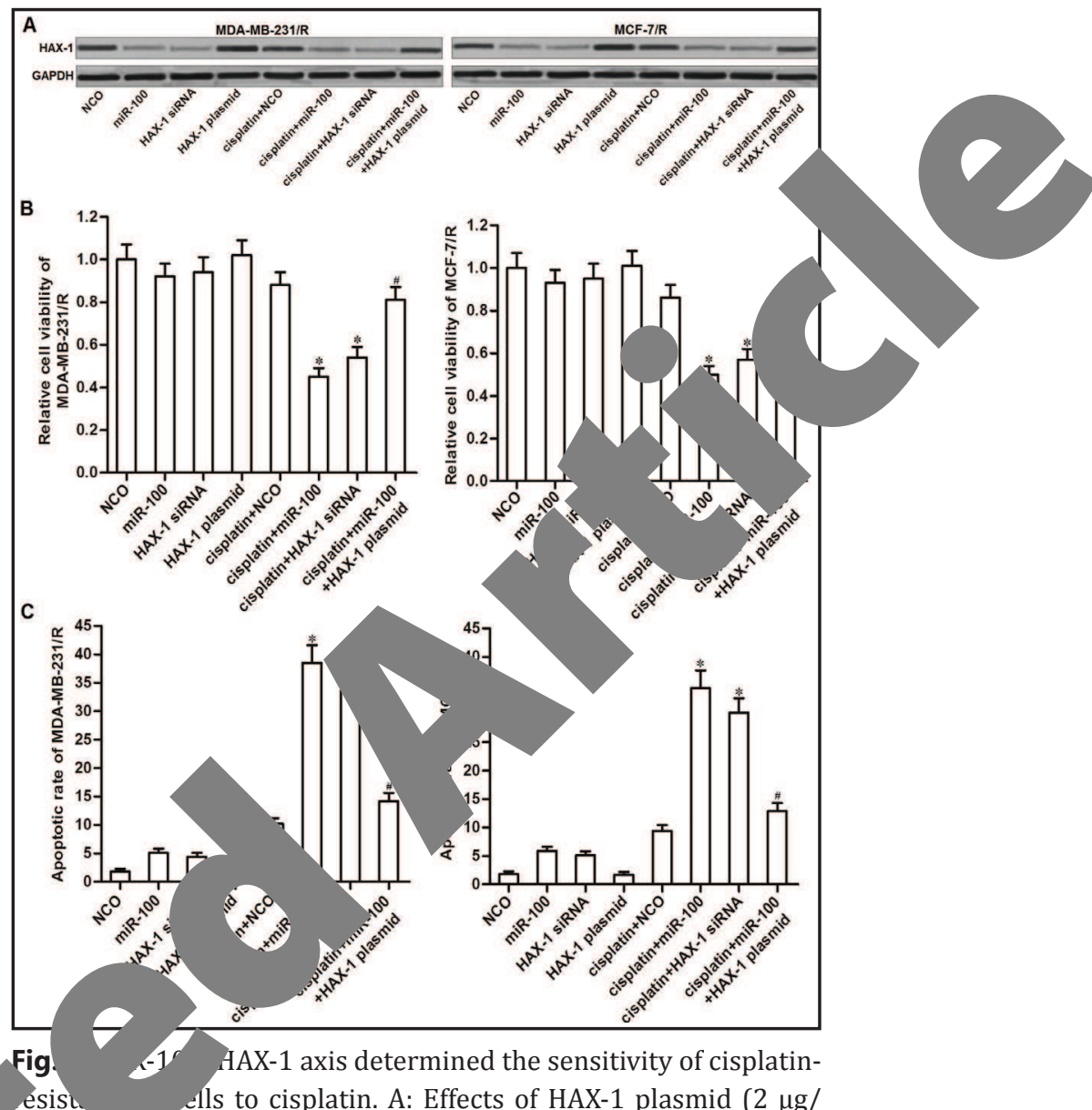
esis $\quad$ ells to cisplatin. A: Effects of HAX-1 plasmid ( $2 \mu \mathrm{g}$ / ) and HAX-1 siRNA (50 pmol/mL) on changes in HAX-1 protein on in MDA-MB-231/R and MCF-7/R cells. B: Effects of HAX1 prasmid ( $2 \mu \mathrm{g} / \mathrm{mL}$ ) and HAX-1 siRNA (50 pmol/mL) on changes sensitivity of MDA-MB-231/R and MCF-7/R cells to cisplatin $(10 \mu \mathrm{M})$ treatment $\left({ }^{*} \mathrm{P}<0.05\right.$ vs. cisplatin + NCO group; ${ }^{*} \mathrm{P}<0.05$ vs. cisplatin + miR-100 group). C: Effects of HAX-1 plasmid ( $2 \mu \mathrm{g} /$ $\mathrm{mL}$ ) and HAX-1 siRNA (50 pmol/mL) on changes in sensitivity of MDA-MB-231/R and MCF-7/R cells to cisplatin-induced (10 $\mu \mathrm{M}$ ) apoptosis $\left({ }^{*} \mathrm{P}<0.05\right.$ vs. cisplatin $+\mathrm{NCO}$ group; ${ }^{*} \mathrm{P}<0.05$ vs. cisplatin + miR-100 group).

in and miR-100. Taken together, these results demonstrated that expression niR-100 increased the sensitivity of cisplatin-resistant BC cells to cisplatin-induced Ait hondrial apoptosis by suppressing the HAX-1 pathway.

Expression of miR-100 improved the anti-tumor effects of cisplatin in cisplatin-resistant $B C$ models in vivo

To investigate the effects of exogenous miR-100 on improving the anti-tumor effects of cisplatin in cisplatin-resistant BC model in vivo, MDA-MB-231/R cells transfected with empty lentivirus (LV-empty) or lentivirus carrying miR-100 precursor (LV-miR-100) were inoculated into nude mice. Mice inoculated with LV-empty-transfected MDA-MB-231/R cells exhibited obvious resistance to cisplatin treatment. However, mice transfected with miR100-overexpressed MDA-MB-231/R cells showed more sensitivity to cisplatin treatment (Fig. 6A). After euthanasia, the tumor tissues were resected to detect miR-100 and HAX-1 

Cellular Physiology Cell Physiol Biochem 2018;47:2077-2087 and Biochemistry Published online: July 04, $2018 \quad$\begin{tabular}{l|l} 
D 2018 The Author(s). Published by S. Karger AG, Basel \\
wwwk kargercom/cpb
\end{tabular}

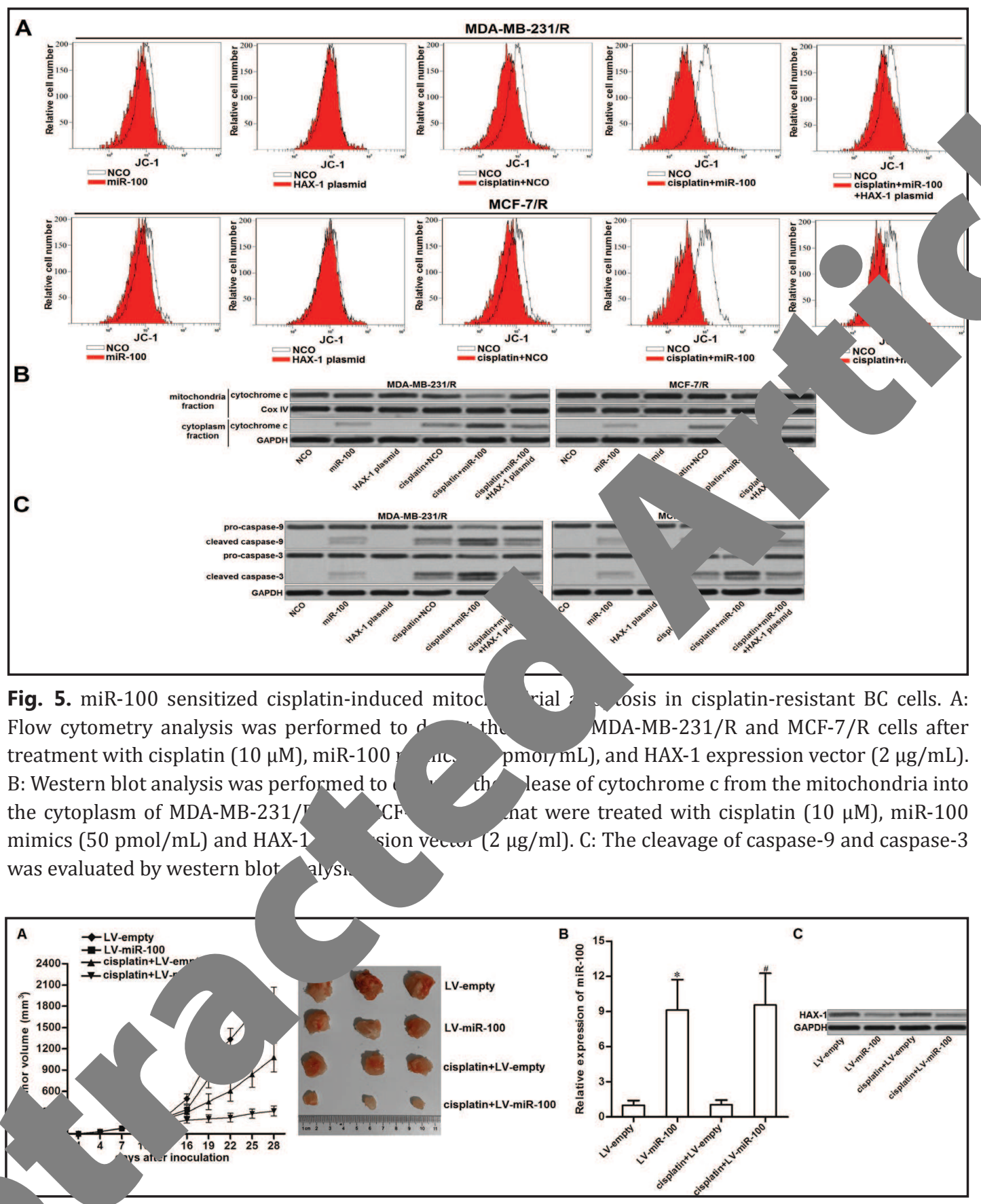

3. 6xpression of miR-100 improved the anti-tumor effects of cisplatin on cisplatin-resistant BC models in A: Nude mice $(\mathrm{n}=24)$ were inoculated with LV-empty-transfected or LV-miR-100-transfected MDA-

231/R cells before treatment with $5 \mathrm{mg} / \mathrm{kg}$ cisplatin twice a week. Tumor volumes were detected every 3 days until euthanasia (28 days post-injection). B: Quantitative reverse transcription PCR assays were performed to detect the expression of miR-100 in tumor tissues resected from tumor-bearing mice $\left({ }^{*} \mathrm{P}<0.05\right.$ vs. LV-empty group; ${ }^{\#} \mathrm{P}<0.05$ vs. cisplatin $+\mathrm{LV}$-empty group). C: Western blot analysis was performed to evaluate the protein expression of HAX-1 in tumor tissues resected from tumor-bearing mice.

expression. Tissues from mice inoculated with LV-miR-100-transfected cells had significantly higher levels of miR-100 than tissues from mice inoculated with LV-empty-transfected cells (Fig. 6B). Conversely, the protein expression of HAX-1 in mice inoculated with LV- 


\section{Cellular Physiology \\ Cell Physiol Biochem 2018;47:2077-2087 and Biochemistry

MB-231 and MCF-7 BC cell lines. Interestingly, restoration of miR-100 in these cisplatin-resistant BC cells reversed cisplatin resistance both in vitro and in vivo. Thus, restoring miR-100 expression in cisplatin-treated cells may be a potential approach for reversing the chemoresistance of $\mathrm{BC}$ cells.

In cisplatin-induced cytotoxicity against cancers, induction of apoptosis pathway is an important mechanism $[30,31]$. Among the cellular proteins that regulate the apoptosis pathway of cancer cells, HAX-1 is a key antiapoptotic protein located in the mitochondria [32]. Previous studies have shown that HAX-1 maintains the $\Delta \Psi_{\mathrm{m}}$ and suppresses MOMP $[33,34]$. Therefore, cellular HAX-1 inhibits mitochond apo ws in cancer cells. Recent studies have demonstrated that overexpression sponsible for chemoresistance in a variety of cancers including esophag se rous carcinoma, laryngeal cancer, and breast cancer [35-37]. HAX-1 is considered get for improving the efficiency of chemotherapy. In this study, the ove tion of cisplatin resistance in tial strategy for enhancing èm

hus, inmolting HAX-1 expression may represent a poten-
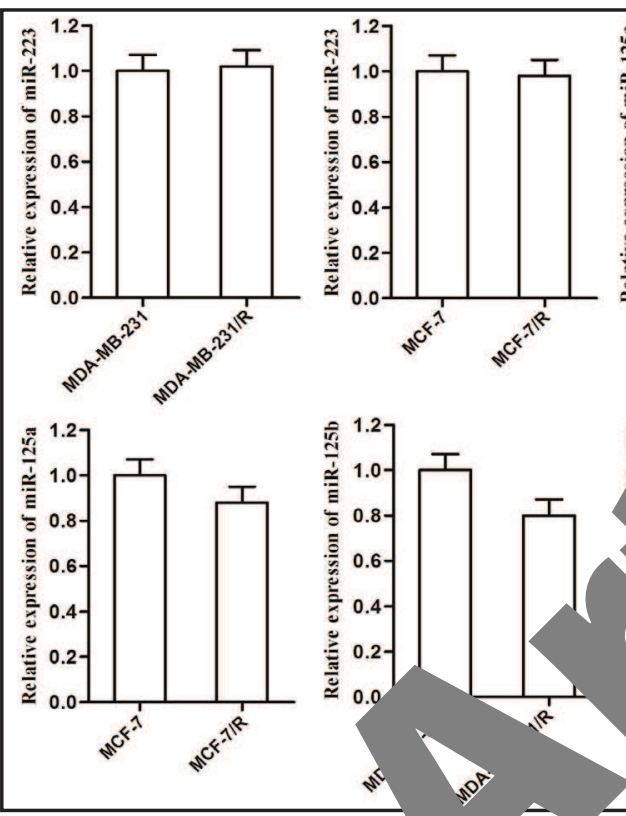

Fig. 8. Relative pression of $\mathrm{m}$ MDA-MB-231, B-231/R, M

3, miR-125a, and miR-125b in

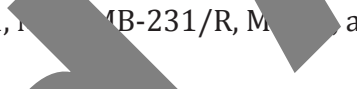
and MCF-7/R cell lines.

Previous studies hay miR-125b, and miR-223 miR-223 expression hetv atin-resistant BC cells and their parental cells. Meanwhile,
the reduction

portea AAX-1 can be regulated by miRNAs such as miR-125a, $38,9]$. However, we did not observe a significant difference in expression wa 19 BC cells became cisplatin-resistant (Fig. 8). Mechanistically, our data show tha AX overexpression was induced by decrease of miR-100 in cisplatinresistap cells. oration of miR-100 was able to suppress the aberrant expression of Y $4 X-1$ latin-resistant BC cells, thereby resensitizing these cells to cisplatin-induced 1ona. goptosis through suppression of HAX-1 expression.

velaph nnt of cisplatin resistance in cancer cells usually induces resistance to platinum deriv 40]. In our study, we also observed the resistance of cisplatin-resistant BC cells arboplatin and oxaliplatin. However, combination treatment with miR-100 reversed the es "ance to these platinum-based anti-tumor drugs.

faken together, the results of this study provide strong evidence that the miR-100/ AX-1 axis is associated with chemoresistance to platinum-based anti-tumor drugs in BC. Combination treatment with miR-100 may represent an effective approach for improving the anti-tumor effects of platinum-based chemotherapeutic drugs in BC.

\section{Acknowledgements}

This study was supported by the Natural Science Foundation of Shandong Province (grant no. ZR2014HM115) and Scientific Research Project of Shandong University (grant no. 12721742). 


\section{Cellular Physiology Cell Physiol Biochem 2018;47:2077-2087 \begin{tabular}{c|c|c|c|}
\hline DOI: 10.1159/000491476 & (c) 2018 The Author(s). Published by S. Karger AG, Basel \\
and Biochemistry Published
\end{tabular}}

Wu et al.: miR-100 Reverses Cisplatin Resistance

\section{Disclosure Statement}

The authors declare no conflict of interests.

\section{References}

Siegel R, Naishadham D, Jemal A: Cancer statistics, 2013. CA Cancer J Clin 2013;63:11-30.

2 Scully OJ, Bay BH, Yip G, Yu Y: Breast cancer metastasis. Cancer Genomics Proteomics 2012.

-3 King TA, Morrow M: Surgical issues in patients with breast cancer receiving neoadjuvant c Nat Rev Clin Oncol 2015;12:335-343.

4 Vergine M, Scipioni P, Garritano S, Colangelo M, Di Paolo A, Livadoti G, Maturo A, Mont conserving surgery after neoadjuvant chemotherapy in patients with locally advanced results. G Chir 2013;34:254-256.

5 He H, Tian W, Chen H, Jiang K: MiR-944 functions as a novel oncogene and regulote ê chen breast cancer. Tumour Biol 2016;37:1599-1607.

6 Liu Y, Du F, Chen W, Yao M, Lv K, Fu P: EIF5A2 is a novel chemoresi gene in b Cancer 2015;22:602-607.

7 O'Grady S, Finn SP, Cuffe S, Richard DJ, O'Byrne KJ, Barr MP: The ro resistant lung cancer. Cancer Treat Rev 2014;40:1161-1170.

8 Roh JL, Park JY, Kim EH: XI-011 enhances cisplatin-i head and neck cancer. Apoptosis 2014;19:1594-160

-9 Jia S, Chaibou MA, Chen Z: Daintain/AIF-1 reinforces th Biotechnol Biochem 2012;76:2338-2341.

10 Xie Q, Wang S, Zhao Y, Zhang Z, Qin C, Yang X: MiRcells by down-regulating the expression of

ance of breast cancer cells to cisplatin. Biosci Yin $S, X u$ Yin S, Xu L, Bonfil RD, Banerjee S, Sarkar
major role in drug resistance in triple-n Reday KB: Tumor-initiating cells and FZD8 play a

12 Bartel DP: MicroRNAs: target Li XJ, Ren ZJ, Tang JH, Yu Q: Ex $\quad$ MicrokrvarviR-1246 Promotes Cell Proliferation, Invasion and Drug Resistance by Targeting CC 2 in cer. Cell Physiol Biochem 2017;44:1741-1748.

14 Lu X, Ma J, Chu J, Shao Q ng Y, Lu u, Auang X, Li W, Li Y, Ling Y, Zhao T: MiR-129-5p Sensitizes the Response of Her-2 I ve Bre ct Cancer to Trastuzumab by Reducing Rps6. Cell Physiol Biochem 2017;44:2346-2356

15 Wang X, Chen Jing n, Lu H, Yang Y, Cai L, Zhao Y: MiR-181b regulates cisplatin chemosensitivity and metast TGFßR1/Smad signaling pathway in NSCLC. Sci Rep 2015;5:17618.

16 Zhou S ang en Lin K, You J, Zhang X: miR-27a regulates the sensitivity of breast cancer cells to cisn reatm BAK-SMAC/DIABLO-XIAP axis. Tumour Biol 2016;37:6837-6845.

17 hiva hittgen TD: Analysis of relative gene expression data using real-time quantitative PCR and the -Delta C(T)) method. Methods 2001;25:402-408.

ng J,Tià, X, Han R, Zhang X, Wang X, Shen H, Xue L. Liu Y, Yan X, Shen J, Mannoor K, Deepak J, Donahue SA, Xing L, Jiang F: Downregulation of miR-486-5p contributes to tumor progression and metarlasis by targeting protumorigenic ARHGAP5 in lung cancer. Oncogene 2014;33:1181-1189. Drathapan A, Vineetha VP, Raghu KG: Protective effect of Boerhaavia diffusa L. against mitochondrial dysfunction in angiotensin II induced hypertrophy in H9c2 cardiomyoblast cells. PLoS One 2014;9:e96220. Sheng C, Ni Q: Expression of HAX1 and Ki-67 in breast cancer and its correlations with patient's clinicopathological characteristics and prognosis. Int J Clin Exp Med 2015;8:20904-20910. Trebinska A, Rembiszewska A, Ciosek K, Ptaszynski K, Rowinski S, Kupryjanczyk J, Siedlecki JA, Grzybowska EA: HAX-1 overexpression, splicing and cellular localization in tumors. BMC Cancer 2010;10:76.

-22 Yang J, Wu Y, Wang X, Xu L, Zhao X, Yang Y: Chemoresistance is associated with overexpression of HAX1 , inhibition of which resensitizes drug-resistant breast cancer cells to chemotherapy. Tumour Biol 2017;39:1010428317692228.

-23 Bi Y, Jing Y, Cao Y: Overexpression of miR-100 inhibits growth of osteosarcoma through FGFR3. Tumour Biol 2015;36:8405-8411. 


\section{Cellular Physiology Cell Physiol Biochem 2018;47:2077-2087

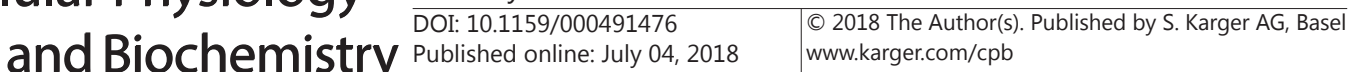

Wu et al.: miR-100 Reverses Cisplatin Resistance

24 Luan Y, Zhang S, Zuo L, Zhou L: Overexpression of miR-100 inhibits cell proliferation, migration, and chemosensitivity in human glioblastoma through FGFR3. Onco Targets Ther 2015;8:3391-3400.

25 Zhou MK, Liu XJ, Zhao ZG, Cheng YM: MicroRNA-100 functions as a tumor suppressor by inhibiting Lgr5 expression in colon cancer cells. Mol Med Rep 2015;11:2947-2952.

26 Gong Y, He T, Yang L, Yang G, Chen Y, Zhang X: The role of miR-100 in regulating apoptosis of breast cance cells. Sci Rep 2015;5:11650.

27 Chen P, Xi Q, Wang Q, Wei P: Downregulation of microRNA-100 correlates with tumor progression and poor prognosis in colorectal cancer. Med Oncol 2014;31:235.

28 Cao YH, Zhang HH, Xu HF, Duan YJ, Li Q Huang B: Prognostic role of microRNA-100 in patientc with bl cancer. Genet Mol Res 2015;14:15948-15954.

29 Chen P, Zhao X, Ma L: Downregulation of microRNA-100 correlates with tumor progression an prognosis in hepatocellular carcinoma. Mol Cell Biochem 2013;383:49-58.

-30 Yan M, Ni J, Song D, Ding M, Huang J: Activation of unfolded protein response protects from cisplatin-induced apoptosis through NF- $\kappa B$ pathway. Int J Clin Exp Pathol 2015

-31 Zhao JX, Liu H, Lv J, Yang XJ: Wortmannin enhances cisplatin-induced apoptosis in cells in vitro. Eur Rev Med Pharmacol Sci 2014;18:2428-2434.

-32 Suzuki Y, Demoliere C, Kitamura D, Takeshita H, Deuschle U, Watan HAX-1, à protein, localized on mitochondria, directly associates with HS1, Immunol 1997;158:2736-2744.

-33 Trebinska A, Högstrand K, Grandien A, Grzybowska EA, Fadeel B: Ex 1 versus BCL-XL in cytokine-dependent bone marro srived cells fro 2927.

-34 Jiang X, Wang X: Cytochrome c promotes caspase-9 act. Biol Chem 2000;275:31199-31203.

-35 Sun SJ, Feng L, Zhao GQ Dong ZM: HAX-1 promote: esophageal squamous carcinoma cells. Dig

-36 Liu J, Tang Q Li S, Yang X: Inhibition of H stem cells. Oncotarget 2016;7:86446-86

-37 Yang J, Wu Y, Wang X, Xu L, Zh 1, inhibition of which resensit 2017;39:1010428317692?

-38 Hu G, Zhao X, Wang J, Lv breast cancer cells to do

>39 Sun X, Li Y, Zheng M. Zuo $\operatorname{ang} \mathrm{C}, \mathrm{Fe}$

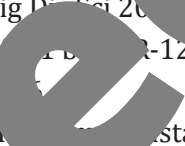
hem stance, invasion, and tumorigenicity of 8-1846.

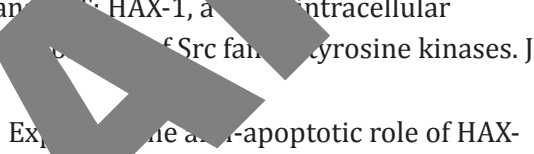
ice. FEBS Lett 2014;588:2921-
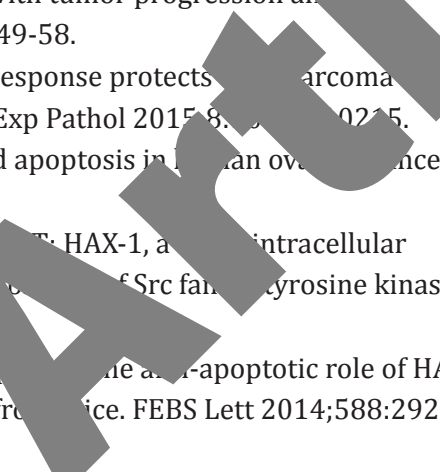
icer

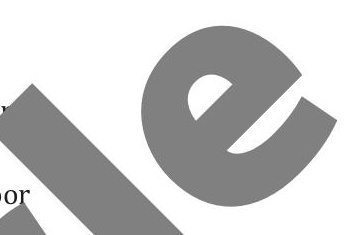

